\title{
LATÍN TARDÍO Y ROMANCE TEMPRANO (1982-88)
}

\author{
ROGER WRIGHT \\ Universidad de Liverpool
}

La Revista de Filología Española me hizo un gran honor al publicar (RFE, LXIV, 1984, 129-45) la reseña de mi libro Late Latin and Early Romance in Spain and Carolingian France. Raras veces se dedica tanto interés en estas páginas a un estudio inglés. Aunque Francisco Marcos tenía sus reservas, concluyó la reseña así: "el trabajo es valioso y merece la pena meditarlo y discutirlo". Ahora sale la traducción castellana; así que me parece oportuno considerar aquí algunos de los temas planteados allí por F. Marcos y en otras reseñas de la versión inglesa ${ }^{1}$.

La tesis central del libro es ésta: que la distinción que se hace actual-

1 Liverpool, Francis Cairns, 1982; Latin Tardio y Romance Temprano, en la Biblioteca Románica Hispánica de Gredos; la castellana es mera traducción del original, bien hecha por Rosa Lalor, sin revisión. Por si es de interés, he aquí una lista de las 21 reseñas del $L L E R$ que he visto, ordenadas aproximadamente de la más favorable a la más hostil. John Green, The Year's Work in Modern Language Studies, XLIV, 1984, 14-15. José-Luis Moure, Incipit, III, 1983, 224-30. Paul Lloyd, Hispanic Reviene, LII, 1984, 367-77. Marc Van Uytfanghe, Francia, XI, 1984, 611-13. Robert Blake, Hispanic Linguistics, II, 1985, 161-66. Suzanne Fleischman, Speculum, LIX, 1984, 222 25. Nicholas Round, Journal of Ecclesiastical History, XXXVIII, 1987, 449-52. Fred Hodcroft, Medium Aevrum, LIV, 1985, 132-33. Steven Kirby, La Corónica, XII, 1984, 295-97. Lawrence McCrank, Journal of Library History, XXI, 1986, 612-14. Saul Levin, General Linguistics, 24, 1984, 194-99. Tom Walsh, Romance Philology, XL, 1986, 199214. Frank Nuessel, Language, LX, 1984, 184-85. J. Giot, Les Etudes Classiques, Oct. 1986, 417-18. Arnulf Stefenelli, Révue de Linguistique Romane, XLVII, 1983, 446-47. Francisco Marcos Marín, Revista de Filología Española, LXIV, 1984, 129-45. Michel Banniard, Trames, 1985, 195-208. Ralph Penny, Bulletin of Hispanic Studies, LXI, 1984, 43-45. Helmut Berschin, Zeitschrift für Romanische Philologie, CIII, 1987, 1-8. Bengt Löfstedt, Vox Romanica, XLII, 1983, 259-63. Máximo Torreblanca, Journal of Hispanic Philology, VII, 1983, 141-43.

Tengo noticia de dos más en prensa, no vistas por mí: Ian Michael, Modern Language Review, y R. A. Hall, Forum Linguisticum. 
mente entre el latín y las lenguas romances no se hizo sino después de las reformas carolingias de c. $800 \mathrm{~A}$. C. ; que antes de estas reformas sólo había una lengua, llamada entonces latinus, pero que actualmente se suele llamar "Romance Temprano" o "Protorromance". Los textos escritos se escribían de la única manera que conocian, que ahora se suele llamar "Latín Tardio". Aprendian de los manuales de escribir (Grammaticae) cómo escribir la lengua (proto)romance que hablaban, pero no escribian otra lengua distinta; de la misma manera que el francés escrito y el hablado de hoy día se diferencian pero siguen siendo dos aspectos de la misma lengua. La evolución retardada de las palabras denominadas "cultas" (o "semicultas") se puede explicar sin necesidad de atribuírsela a una capa del habla totalmente arcaica.

Esta única lengua, claro está, tenía que abarcar gran variación dentro de sí, variación geográfica, estilística y sociolingüística, tal como la abarcan todos los grandes idiomas actuales. Esta comparación merece mayor consideración que la que se le dio en el libro; por eso, en el XVIII Congreso Internacional de Romanistas (1986), expliqué más detalladamente las razones de creer que en muchos aspectos la situación sociolingüística del romance temprano, antes del siglo Ix, se parecía a la del francés, del español y del inglés modernos (la conferencia se publicará en la sección de la Mesa Redonda Sociolingüística). Todos los especialistas en esta materia están de acuerdo en que "la variación no sólo es normal, sino necesaria". Hay grandísima variación entre distintos estilos de estos idiomas, sin que exista ahora una capa de habla sistemáticamente arcaica que correspondería a la del latín hablado arcaico que se ha solido postular al lado del romance en los siglos de v a viII. Otros han venido descubriendo lo mismo; Marc Van Uytfanghe, por ejemplo, ha establecido que las $V$ idas de santos se leian en voz alta y que así las entendían incluso los analfabetos del siglo vir (y tiene razón al señalar que en este punto las ideas del $L L E R$ quizás no eran tan nuevas como había pensado su autor). De todas formas, se sabe que todos entendemos muchas cosas que no decimos. También sabemos que los textos escritos no pueden reflejar el habla espontánea, ni siquiera de su autor; por lo cual es muy difícil sacar de los textos conclusiones detalladas y ciertas sobre el habla de sus autores.

Con casi toda esta parte del $L L E R$, que es la teóricamente fundamental, F. Marcos se mostró de acuerdo. Todo lo que se refiere a los años de después de las reformas carolingias (de c. $800 \mathrm{~A}$. C.) es más discutible y de menos importancia teórica; todo lo que se lee en el $L L E R$ sobre los años posteriores al 800 es lo que parecía consecuencia razonable de lo que se habia propuesto ya para antes de las reformas. Ya se sabía que había reformas carolingias. Lo nuevo del LLER puede haber sido el señalar que llevaban consigo consecuencias lingüísticas especificas: no sólo la corrección 
latina escrita, sino la correción latina hablada en contextos formales. Esta se basaba en la pronunciación, al leer el texto prescrito, de un sonido que correspondiera a cada letra ya escrita. Un poco más tarde esto condujo a la elaboración de un nuevo método de escribir (el que llamamos ahora del francés antiguo), creado para estimular la producción de fonética romance del lector. Los historiadores nos aseguran que los textos de los Juramentos de Estrasburgo deben haberse fijado detalladamente de antemano para que los lectores los leyeran después verbatim; quieren estimular la reproducción oral adecuada, y no son representaciones a posteriori de lo que se les oyó decir (como todavía se suele encontrar en los manuales filológicos). En este caso, el rey de los alemanes, que ya sabía leer un texto latino de la manera latina reformada, pero que parece que no sabía hablar bien francés antiguo, era el que tenia que leer el texto "francés"; y específicamente para él se elaboraron los textos "franceses". El escenario que se nos da en las historias cuadra bien con lo que se dice en LLER; lo llama F. Marcos "eminentemente colorista e imaginativo", lo cual me agrada - sin saber si con estas palabras quería elogiar o censurar - porque lo que ha solido faltarles a los estudios de estos Juramentos es precisamente la imaginación histórica bien informada. Se debe señalar aquí que los historiadores de la Edad Carolingia, aunque no estén convencidos de todos los detalles de lo propuesto en el $L L E R$, suelen estar de acuerdo en que la tesis es por lo menos muy posible.

En cuanto a los siglos posteriores a las reformas de c. $800 \mathrm{~A}$. C., se sugiere que los franceses no parecen haber distinguido entre dos lenguas totalmente distintas, el latín y el francés, hasta después de c. 1000. Era una generalización, desde luego, y no es probable que todos los franceses hayan visto las cosas exactamente de la misma manera en el año 950. Algunos especialistas del francés se han mostrado de acuerdo con esta sugerencia, y otros, con F. Marcos, en que la distinción se hacía ya en el siglo nueve. Sigo creyendo lo mismo, pero aquí todo es cuestión de definiciones más que de sustancia, como señalan muy acertadamente tanto F. Marcos como Nicholas Round en su muy útil reseña. Empleemos otra vez imaginación histórica partiendo de la situación moderna: los especialistas en fonética que transcriben el castellano o el inglés con alfabeto fonético, ¿ piensan que así lo van traduciendo a otra lengua naciente? ¿O que van trasladando el texto a otra manera de transcribir la misma lengua? (Ya se sabe que se suele modificar la morfosintaxis hablada de cualquier lengua al escribirla: en esto no hay problema.) Surge el mismo problema en cuanto a España, aunque más tarde. Sigo creyendo que sólo podemos estar seguros de que los españoles concebían el romance español como lengua enteramente distinta del latín en el siglo trece, y que los documentos al parecer bilingües o híbridos del siglo 
anterior (el $\mathrm{x} I \mathrm{I})$, que ahora parecen mezclas de romance y latín, representan la lengua vernácula con añadiduras profesionales sobrepuestas por los escribas, más que una mezcla de dos lenguas, representada por escribas que eran a la vez fonetistas expertos y bilingües ineficaces. Esta no era idea nueva, de todas formas (y véase ahora el estudio de Blake, 1987). Pero si no convence, y si se quiere postular todavía una clara distinción conceptual entre los españoles del siglo xiI, me parece menos probable, pero no de importancia fundamental, ni contraria a la tesis general.

La situación lingüística que se puede vislumbrar en España, entre la época de las reformas carolingias y el siglo xiII, se representaba en el LLER de una manera sencilla: antes de la reforma del rito (1080) sólo había una lengua en la Iberia no-catalana, igual que en los siglos I-viII, con las grandes variaciones que se señalan aquí arriba. Así que no se le da crédito alguno al postulado "latín vulgar leonés". Pero este tema merecía ejemplificarse más, de manera que lo volví a desarrollar después, en castellano, en la revista argentina Incipit. F. Marcos nos asegura que ni Lapesa sigue dando crédito al concepto del "latín vulgar leonés"; menos mal, y no hay que insistir más en esto ahora (y a Manuel C. Díaz y Díaz le he oído decir que aunque los españoles del siglo $x$, en su opinión, sí usaban las dos lenguas, no sabian que lo hacian).

Sin embargo, las célebres glosas riojanas permanecen tan enigmáticas como siempre. F. Marcos dice, con plena razón [4.3] : "los glosadores, evidentemente, no eran ignorantes; pero tampoco sabemos qué eran, o por qué, exactamente, lo hicieron". Es cierto que en el $L L E R$ se les dedicaron muchas páginas a las Glosas sin establecer lo que eran. Más tarde las volví a estudiar para el XVII Congreso de Romanistas (en un estudio ya publicado en las Actas), pero todavía, hay que confesarlo, parecen bastante raras. Allí se elabora la idea de que las glosas de apariencia romance se escribieran así para un extranjero - a lo mejor, catalán o francés- que no sabía el romance riojano, pero que quería tal vez leer allí en voz alta de manera inteligible. Desde luego, no habrían sido estas glosas de ninguna utilidad para un riojano; todo riojano que supiera leer habría reconocido mejor las palabras con su ortografía normal (no es fácil leer en voz alta las transcripciones fonéticas, ni siquiera para un especialista). Se propuso que, al elaborar las glosas al parecer "romances", se hubiera empleado la misma técnica que la que se emplea hoy día en los libros de frases destinados a los turistas que no saben la lengua, esto es, transcribir palabras de una lengua o dialecto con la ortografía que corresponde a otra. Así, para los turistas ingleses que no sepan el portuguẹe, se transcribe obrigado ("gracias") así: oo-bree-gáhdoo, para que un inglés lo pueda leer según las reglas inglesas con la esperanza de que así reconozcan la palabra los portugueses que le oigan. (Se ha 
hecho algo igual para los londinenses que quieran hablar el inglés de $\mathrm{Li}$ verpool.) Así puede ser que se escribiera kematu siegat (Glosa Silense n. ${ }^{0}$ 9) en vez de cremetur, como glosa del comburatur textual, para hacer que el forastero profiriera [kemado sjeja] (o algo así). Pero el problema no se ha resuelto enteramente, y conviene más que lo estudie un riojano; con la cuidada edición de Las Glosas Emilianenses de García Larragueta ya será menos imposible que antes. Naturalmente, hay que estar de acuerdo con Díaz y Díaz en que son del siglo once.

El rito romano y su latín nuevo -ahora llamado "latín medieval", pero entonces llamado litterae - se introdujeron en la España no-catalana después del concilio de Burgos de 1080. En la última parte del LLER se estudia solamente este proceso y sus consecuencias. No se pretende en él ofrecerles a los lectores un panorama general de la literatura y cultura hispánicas de los siglos once al trece. Unicamente se trata de lo que parece relacionarse con el problema central del $L L E R$, de cómo y cuándo se distinguían el latín y el romance como dos lenguas distintas, y nada más. F. Marcos habría preferido que se dedicase el libro a otros muchos temas también, al hispanoárabe, por ejemplo, llamando "patética" a esta limitación: "el autor insiste, hasta lo patético: todos se equivocan, la única explicación es 'la invención del latín medieval' ". Si un fenómeno cultural no tuvo nada que ver con el latín medieval, no se menciona. Unicamente me referí a lo que venía al caso, y esta restricción era más bien práctica que patética (el libro es largo ya). $\mathrm{Ni}$ dije que "todos se equivocan", ni lo creo; pero si tengo algo que decir, lo digo, y si no, me quedo callado. No vale la pena hacer lo que se ha hecho demasiado, esto es, repetir una vez más lo ya consabido. Desde luego, conviene que F. Marcos, o algún otro erudito que tenga la formación necesaria, se ponga a estudiar las implicaciones de la tesis en cuanto al hispanoárabe (y vice versa). Ya consideré de paso por qué.los árabes parecen haberse referido a la lengua hablada de los cristianos de Al-Andalus como Al-Lathini, en mi estudio (1988) sobre la palabra ladino (parece que los de habla romance seguían refiriéndose a esta habla con la palabra [ladino], escrito latinu-, aún hasta el siglo trece).

F. Marcos criticó severamente la Bibliografía final. Se entiende por qué lo hizo. El LLER se concibió no como libro pedagógico (como lo son los libros de F. Marcos), sino de investigación. La bibliografía no es nada más que la lista alfabética de los estudios que se citan en el texto, y sólo se incluyeron en el texto referencias que venían al caso específico. Por eso no es una bibliografía exhaustiva de todos los libros del campo entero, la cual, por lo demás, llenaría otro libro. (Aunque, claro, de saber que F. Marcos lo reseñaría, se habría incluido algún libro suyo.) Tampoco es bibliografía recomendada, porque se hace alusión a algunos libros solamente para criti- 
carlos; p. ej., se incluye el libro de Laza Palacio sólo porque una de sus ideas se calificó de "absurda". Hay también que advertir que el libro se preparó entre los años 1977-81 y que salió en 1982, de modo que no se le puede censurar con justicia por no hacer referencia a estudios que aparecieron más tarde (p. ej., F. Marcos habría querido que se mencionara Lapesa 1983). Igualmente, el estudio de Lapesa "Sobre el Cantar de Mío Cid. Crítica de críticas. Cuestiones lingüísticas" tampoco lo leí a tiempo, pero es sin duda excelente (dicho para tranquilizar a F. Marcos; Lapesa ya sabe lo mucho que le admiro) y la réplica de Pattison poco convincente. (Esta lista de referencias queda igual en la versión española, traducción sin revisión.)

No hay nada insólito en que a un autor se le critique por no haber leído estudios que no podía leer a tiempo, y no hay que quejarse al recibir tal crítica. Pero si sorprende mucho que a un autor se le critique específicamente por haberse referido a un libro que salió mucho después del suyo. F. Marcos me critica duramente por hacer "críticas parciales a Colin Smith", refiriéndose al libro de éste que salió en 1983 (que se recibió en el mundo anglosajón con la misma mezcla de admiración y de escepticismo que en otras partes). Pero no me referí a este libro en absoluto. Era imposible. El LLER salió en 1982. Además, en el $L L E R$ no se le hacen críticas favorables; se menciona seis veces a Colin Smith, cinco sólo para advertir que no estoy de acuerdo con algo que escribió. Colin Smith es erudito eminentemente amable, cortés y simpático, pero ni siquiera él me llamaría a mí uno de sus "seguidores". Por ejemplo, acaba de publicar un estudio en que muestra no estar de acuerdo con lo que se dijo en mi edición del Carmen Campi Doctoris. (Pero este error de F. Marcos, compartido por Armistead, se entiende mejor que el que cometió Hall al acusarme de ser seguidor de Muller, al que en realidad critico severamente.) Además, aunque tuviera razón en esto F. Marcos, no se ve que esto sea en sí motivo de desaprobación. En verdad la tesis del $L L E R$ es más o menos neutral en el debate de si y de cómo existió el Poema de Mio Cid en el siglo xII.

En cuanto a la escritura del romance durante este siglo xII, F. Marcos escribe [5.3]: "la seguridad de las grafías empleadas en estos trabajos" (sc. de 1206-07) "debió hacerle pensar en una larga práctica previa"; y así pensé, exactamente lo mismo, y lo que se dijo en $L L E R$ (págs. 240-41; $L T R T$, págs. 358-59) era precisamente lo que F. Marcos me critica por no haber pensado. También parece que F. Marcos cree [nota a 4.3] que yo censure a los españoles por haber resistido esta influencia francesa hasta tan tarde, pero no es así. Es más, los elogio por su individualidad. No hay por qué pensar que la herencia visigótica fuera de ninguna manera menos loable que la carolingia. Los que recobraban aquélla en el reinado de Fer- 
nando I y después (p. ej. San Martín de León), y los mozárabes que querían aferrarse a sus tradiciones en el Toledo de después de 1085, estaban totalmente justificados en su patriotismo. $\mathrm{Y}$ resistieron con mucho mayor éxito que los ingleses.

Todavía refiriéndose a la bibliografía, F. Marcos señala que se encuentran allí demasiados libros y artículos escritos en inglés, y que deberian de haberse incluido más en lenguas ibéricas. El libro se escribió para angloleyentes, e, incluso de ser ciertas las matemáticas, a lo mejor esta falta se podría perdonar. Pero la crítica parece - dicho muy suavemente- inaceptable. En los capítulos cuatro y cinco, los que se refieren específicamente a España, se encuentran 172 referencias hechas a estudios escritos en español y 83 a estudios escritos en inglés (más 18 en francés, 8 latín, 5 alemán, 4 catalán, 3 italiano). En los dos primeros capítulos, que tratan de los idiomas romances en general, me he referido mucho más al español que a ningún otro idioma. Y esto no es lo normal. Se han escrito muchos libros de filología románica, en alemán, francés, inglés, que centran su atención en el francés, y a veces el italiano, pero apenas para nada en las lenguas ibéricas. Los franceses e italianos me podrian criticar por mi obsesión hispánica -aunque, en realidad, sólo Stefenelli ha mencionado este desequilibrio, sin hostilidad-. Y los alemanes se podrían quejar aún más de la falta de estudios alemanes mencionados en el capítulo tres, el carolingio. Pero nada de esto tiene gran importancia. No se trata del concurso de Eurovisión. Y dedico mi vida profesional a la enseñanza y la difusión de la cultura hispánica. Conste que soy hispanófilo.

Debe constar también que F. Marcos es anglófilo. Necesita subrayarse, porque algunos ingleses -que también a nosotros se nos permite leer la $R F E$ - han tomado a mal la parte final de la reseña, en que nos critica por no saber leer el español con la facilidad que teníamos hace treinta años [7.1] (en mi caso, no tiene razón; hace treinta años no sabía yo leer ni palabra de castellano). John Green, por ejemplo, el mejor de los especialistas ingleses de lingüística española, calificó la reseña de malhumorada y xenófoba ("grumpy and xenophobic", 1986:36). Lo cual es un poco injusto. Pero, en respuesta a las preguntas finales de F. Marcos, se le puede contestar que sí, hay una crisis actual en la enseñanza de todas las lenguas extranjeras en los colegios británicos. Aunque se firmó un acuerdo europeo que pretendió asegurar que todos los escolares de los países europeos tendrían que aprender otras dos lenguas comunitarias, el gobierno inglés intenta imposibilitar que se estudien dos lenguas a la vez antes de la edad de dieciséis años; $y$ ha querido reducir el número de universidades en que se enseña el español de 36 a 26. Los hispanófilos acogeremos toda la ayuda española que F. Marcos recomendó que se nos preste. 
No emprendí estas líneas con la mera intención de mirar hacia el pasado. El $L L E R$ (ya $L T R T$ ) lo tendrán los castellanoleyentes. Podrá suscitar muchas direcciones de investigación nuevas y problemas filológicos que convendría más que los atacaran los lingüistas hispanohablantes. Las palabras denominadas "cultas" y "semicultas", por ejemplo, que se sugiere que podrán explicarse según las técnicas normales de la lingüística histórica. ¿Se puede establecer, en cada caso, cuándo llegaron al vocabulario castellano? ¿Se podría especular por qué tantos términos eclesiásticos han evolucionado más de lo normal, como la o- de obispo y la ig-de iglesia? ¿Hasta qué punto se puede conceder que en el romance la irregularidad fonética histórica sea fenómeno completamente normal, dados los conceptos de la "Difusión Léxica" de los cambios? El norteamericano Lee Hartman ya ha empezado a tomar en cuenta las sugerencias del $L L E R$, al elaborar su tentativa muy interesante de programar para su ordenador las reglas del cambio de sonido que se dieron en Castilla. Sería muy útil que hiciese algo igual Carmen Pensado Ruiz, por ejemplo, cuyo libro extraordinario no pude consultar a tiempo. Y la morfología sigue pareciendo un poco enigmática; como han mostrado algunos (p. ej. Penny), se habría podido esperar que hubiera habido grandes diferencias morfológicas entre el habla de los literatos y la de los analfabetos en la España de los siglos vi-x, porque aquéllos conocían las Grammaticae que detallan la morfología arcaica, y la empleaban al escribir y al releer lo ya escrito; pero cuando llegamos a poder ver claramente la morfología del español (en los textos del siglo XIII) no hay ninguna indicación de que los literatos, que escribían los textos, tuvieran en su lengua hablada (p. ej.) pasivas sintéticas, sustantivos neutros, casos genitivos, ni otras desinencias ya desaparecidas del habla general. Es más, los pretéritos "fuertes" pertenecen por lo común a palabras muy corrientes (dije, fui, etc.); aunque hay la tendencia general de regularizar los paradigmas, los que quedan sin cambiar no son en absoluto propiedad exclusiva de los "cultos". Esto sorprende mucho, y significa que la parte morfológica del $L L E R$ es la parte más firme, lo que no se habría esperado de antemano. Sería de interés que un especialista en las Gramáticas se dedicase a estudiar exactamente cómo se usaban; tenían que usarse de alguna manera al aprender a escribir, pero ¿ por qué la morfología elaborada en ellas con tanto esmero no parece haber influido para nada en el habla de los que las estudiaban? En general, sería aconsejable que los gramáticos mismos fueran estudiados detalladamente por filólogos románicos. $\mathrm{Y}$ es bien posible que se puedan aducir y estudiar más datos sobre el latín/romance de los siglos muy tempranos escrito en alfabeto griego, árabe o hebreo; los que han sido estudiados hasta ahora (p. ej. por Sabatini) parecen ser representaciones de habla romance, pero queda mucho por hacer. También, aunque 
ya se ha hecho bastante, se pueden estudiar más detalladamente los préstamos tomados del latín al beréber, al albanés, al galés, etc., teniendo en cuenta la tesis del LLER.

En cuanto a los textos visigóticos: ¿ será posible animar a los editores modernos a que no "corrijan" automáticamente los manuscritos de modo que apenas quepa ver lo que realmente se escribió? ¿ Se puede averiguar más claramente lo que Julián de Toledo quería decir al escribir sobre la poesía rítmica? No sé si existen abogados castellanos de formación tanto filológica como sociolingüística, pero conviene que alguien con esa preparación compare los textos medievales tempranos con los de hoy, para asegurarse de si las hipótesis de Sabatini (usadas extensamente en el $L L E R$ ) de veras parecen razonables a la luz de las prácticas modernas. $Y$ con respecto a los himnos de la misma época : ¿hay filólogos a la vez especialistas en música medieval que deseen dedicarse a considerar hasta qué punto se puede deducir la pronunciación y la silabificación probables de los textos cantados antes de las reformas carolingias? (Se sabe que después solían adecuar una nota de música para cada sílaba del latín reformado, pero no se puede esperar que haya sucedido lo mismo antes.) ¿Se puede evaluar la situación sociolingüística postulada en el $L L E R$ para la España del siglo $\mathrm{x}$ según las técnicas más al día? (Ojalá esto lo hiciera Carmen Silva Corvalán, cuyos estudios recientes son de tanto valor.) Un historiador imaginativo podrá iluminar más las técnicas de los cristianos de Al-Andalus: cuando escribieron, ¿usaban otra lengua distinta de la que hablaban (como cree F. Marcos), o más bien iban construyendo cautelosamente producciones literarias a base de la suya vernácula (como se sugiere en el $L L E R$ )? Los catalanes, ¿es verdad que se contentaron durante siglos con seguir una norma provenzal de escritura vernácula? Es posible; al escribir, los leoneses usan una norma castellana, por ejemplo. Se ha solido llamar a la temprana escritura romance "catalán provenzalizado" en vez de norma occitana levemente catalanizada, y a lo mejor los historiadores de Cataluña sabrian decir si esta hipótesis, la del $L L E R$, se ajusta a los hechos históricos. Convendría a la vez que los historiadores investigaran los documentos de muchas áreas geográficas para decidir si se puede postular razonablemente que las influencias francesas en la Iberia no-catalana antes del año 1072 no incluian la enseñanza del latín. Roger Collins ya ha estudiado documentos del siglo $\mathrm{x}$ en parte desde este punto de vista lingüístico. $Y$ tiene que estudiarse más lo que José Antonio Puentes Romay ha empezado ya a investigar, esto es, si hay consistencia de método entre los escribas de un área en los siglos nueve y diez.

Una sugerencia del $L L E R$ a la que nadie parece haber prestado atención es la de que la poesía denominada "rítmica" de La Rioja del siglo diez no tenía nada que ver con el ritmo, ni con ningún otro fenómeno del habla, 
sino que Vigilán y sus colegas riojanos veían la técnica de la poesia escrita como cosa de matemáticas, nada más, contando sílabas (según se definían las sílabas en las Gramáticas: más o menos, vocales escritas) como contaban letras al elaborar su carmina figurata; conviene que un hispano-latinista lo considere más. Los eclesiásticos de los siglos vili al $x$, ¿sabían distinguir claramente entre el verso y la prosa en la liturgia? En el $L L E R$ se sugiere que no, y que en esto se puede entrever un enlace genuino entre lo litúrgico y la poesia verdaderamente rítmica de la lengua vernácula. Y Diego de Gelmirez, ¿sabía leer el latín a la manera francesa? F. Marcos me critica por hacer hincapié en que la fama de éste se basaba en que "sabía leer al modo carolingio": pero no lo dije, ni siquiera se puede estar seguro de si sabía (quizás F. Marcos ha entendido mal la glosa que hice a un detalle de la Historia Compostelana). Ni siquiera Richard Fletcher (quien alude al $L L E R$ ) se atreve a indicar esto en su excelente biografía del arzobispo, aunque sí señala que escribía Gelmírez con una buena mano visigótica (sic, no carolina, pág. 241). Alegra mucho ver que el historiador Francisco Hernández, en dos estudios fundamentales sobre los documentos toledanos de los siglos XII y XIII, se ha dedicado en parte a iluminar los problemas lingüísticos a que se refiere el $L L E R$; y que Francisco Giménez Menéndez ha hecho un sutil análisis sociolingüístico de la Murcia del siglo xIII, en parte utilizando el LLER; es de esperar que se hagan más estudios semejantes. Se necesita un historiador filólogo que se ocupe de nuevo del Poema de Almeria, sobre todo para decidir si la famosa referencia que se hace allí a la manera castellana de hablar se entiende mejor como una alusión a sus sentimientos independentistas para con el rey de León, el protagonista del Poema (como sugerí), o como una alusión a los diptongos crecientes (como sigue creyendo F. Marcos, 5.2). La datación precisa de cuándo, cómo y por qué, en diversas partes de la Península, se abandonó la caligrafía visigótica para adoptar la carolina, necesita estudiarse con más detenimiento y con relación a la política reformadora de la época. Francisco Rico ha sabido matizar en parte las conjeturas hechas en el $L L E R$ sobre los primeros años del Studium de Palencia, pero queda mucho más por hacer. El Tratado de Cabreros de 1206 (también mencionado por Hernández) merece un estudio lingüistico largo, que sólo se esbozó en el $L L E R$, así como la celebración poética de la toma de Sevilla escrita por Guillermo Pérez de la Calzada (a no ser que esto lo haya hecho ya Juan Gil, que lo anunció hace años). Otros muchos temas españoles merecen volver a estudiarse, tanto a la luz del $L L E R$ como para clarificarlo a su vez.

Además, claro, los especialistas franceses, alemanes e internacionales contribuirán. Chaim Rabín, el eminente filólogo, ha publicado un estudio importante en que compara la arcaizante estandarización y purificación lin- 
güistica carolingia del latín con otras purificaciones semejantes que se llevaron a cabo durante los mismos siglos, con respecto al griego (en el imperio bizantino del siglo IX), al árabe (de los siglos viII-IX de la era común) y al hebreo que se escribía en los países islámicos (en el siglo $\mathrm{x}$ ); en esta última parte nos ilumina un rincón de Al-Andalus de excepcional interés (se la recomiendo a F. Marcos), pero queda por investigar la psicología internacional que contribuía entonces a tanto afán por la estandarización lingüística. Van Uytfanghe y sus colegas de Gante están realizando estudios muy necesarios sobre la lengua de las Vidas de Santos merovingias; cuando se publiquen, nos ayudarán mucho. Pero se necesita que otros especialistas franceses y alemanes averigüen si otros documentos merovingios, y los del imperio carolingio después del año 796, se pueden interpretar mejor a la luz de estas reformas; y si las diferencias que se ven entre los documentos de la primera parte del siglo ix que provienen de Tours y los de otras partes se pueden atribuir a la presencia en Tours de Alcuino y de sus colegas reformadores. Hace falta una comparación exacta entre las formas de los Juramentos de Estrasburgo y lo que se puede saber del latín leído por alemanes del siglo noveno (Castellani se refirió al $L L E R$ en su reciente estudio, sin parecer haberlo entendido). Y como señala Walsh, sería aconsejable encontrar más datos sobre lo que sucedía en los coros de las iglesias carolingias, antes de sentirnos seguros de la explicación dada de la escritura de la Cantilena de Santa Eulalia. Y finalmente, para defender mi rincón geográfico, hay que confesar que una pequeña parte del libro se refiere a las Islas Británicas; el irlandés Damián McManus ha estudiado lo que significan mis ideas para el estudio del latín británico, y la escocesa Anne King viene considerando lo que significan para su estudio de la elaboración inicial de la escritura del anglosajón; pero se podría iluminar más claramente la formación profesional de Alcuino.

Hay más preguntas que respuestas, pues. Saul Levin terminó su reseña con estas palabras acertadas: "Wright ... ha dejado una gran parte de su materia para que la rellenen otros". Así es. Y es de esperar que la mayor parte de esto se haga en España, donde ahora hay tantos lingüistas jóvenes y excelentes.

\section{LISTA DE REFERENCIAS}

Sayunl Armistrad, "Encore les cantilines: Prof. Roger Wright's Proto-Romances", La Corónica, XV, 1986, 52-66.

Robert Blake, "New Linguistic Sources for Old Spanish", Hispanic Review, LV, 1987, 1-12.

Arrigo Castrulant, "Precisazioni sulla lingua dei Giuramenti di Strasburgo", Actes 
du XVIIe Congrès International de Linguistique et Philologie Romanes, Vol. IX, Aix-en-Provence, 1986, 63-83.

Roger Collins, "Visigothic Law and Regional Custom in disputes in early medieval Spain", The Settlement of Disputes in Early Medieval Europe, ed. W. Davies and P. Fouracre, Cambridge, 1986, 85-104.

Manuel C. Dfaz y Difz, Las Primeras Glosas Hispánicas, Barcelona, 1978.

Richard Fletcher, St James's Catapult, Oxford, 1984.

Santos Garcfa Larragueta, Las Glosas Emilianenses, Logroño, 1984.

Juan Gil y Diego Catalán, "Guillelmi Petri de Calciata, Rithmi de Julia Romula seu Ispalensi Urbe (a. 1250)", Anuario de Estudios Medievales, V, 549-58.

Francisco Giménez Menendez, "Caracterización sociolingüística del Libro de los Primitivos Privilegios de Alicante de Alfonso X el Sabio", Studia Historica in honorem Vicente Martinez Morellá, Alicante, 1985, 119-45.

JoHn GREEN, "Romance Linguistics", The Year's Work in Modern Langwage Studies, XLVI, 1986, 35-41.

Robert A. Hall, "From Bidialectalism to Diglossia in Early Romance", Language in Global Perspective, Dallas, 1986, 213-22.

Steven Lee Hartman, "Learned words, popular words and «first offenders»", Studies in Romance Linguistics, ed. O. Jaeggli and C. Silva Corvalán, Dordrecht, 1986, 87-98.

Francisco Hernández, "Las Cortes de Toledo de 1207", Actas del Congreso Científico sobre la Historia de las Cortes de Castilla y León, ed. J. Valdeón, Valladolid, 1987.

-, "Language and Cultural Identity: the Mozarabs of Toledo", Le pluralisme linguistique dans la société médiévale, ed. P. Boglioni, Montréal, en prensa.

Rafael Lapesa, "Sobre el Cantar de Mio Cid. Crítica de críticas. Cuestiones lingüísticas", Etudes de Philologie Romane et d'Histoire Littéraire offertes d Jules Horrent, Lieja, 1980, 213-31.

-, "Mozárabe y catalán o gascón en el Auto de los Reyes Magos", Miscel.lania Aramon i Serra, III, Barcelona, 1983, 277-94.

M. Laza Palacio, La España del Poeta de Mio Cid, Málaga, 1964.

Francisco Marcos Marfin, Reforma y Modernización del Español, Madrid, 1979.

Daxian McManus, "Linguarum Diversitas: Latin and the vernaculars in Early Medieval Britain", Peritia, III, 1984, 151-88.

David Pattison, "Word-formation in the Poema de Mio Cid; a second visit", La Corónica, XIV, 1985, 86-88.

Carmen Pensado Ruiz, Cronología Relativa del Castellano, Salamanca, 1984.

Jose Antonio Puentes Romay, "Notas sobre la grafía de documentos latinos altomedievales", Verba, XIII, 1986, 343-48.

Chaim Rabin, "Massorah and Ad Litteras", Hebrew Studies, XXVI, 1985, 81-91.

Francisco Rico, "La clerecía del mester", Hispanic Review, LIII, 1985, 1-23 y 127-50.

Francersco Sabatini, "Lingua parlata, scripta, e coscienza linguistica nelle origini romanze", XIV Congresso Internasionale di Linguistica e Filologia Romansa (1974): Atti, I, Nápoles, 445-54.

Carmen Sirva Corvalín, "Bilingualism and Language Change: the extension of estar in Los Angeles Spanish", Language, LXII, 1986, 587-608.

Colin Sxirn, The Making of the "Poema de Mio Cid", Cambridge, 1983.

- "The dating and relationship of the Historia Roderici and the Carmen Campi Doctoris", Olifant, IX, 1982 [1986], 99-112. 
Marc Van Uytfanghe, "L'Hagiographe et son publique à l'époque mérovingienne", Studia Patristica, XVI, 1985, 54-62.

Roger Wright, "The First Poem on the Cid-the Carmen Campi Doctoris", Papers of the Liverpool Latin Seminar, II, 1979, 213-48.

-, "La no existencia del latín vulgar leonés", Incipit, III, 1983, 1-7.

, "La función de las glosas de San Millán y de Silos", Actes du XVIIe Congrès International de Linguistique et Philologie Romanes, Vol. IX, Aix-en-Provence, 1986, 209-19.

- "Early Medieval Spanish, Latin and ladino", Litterae Judaeorwon in Terra Hispanica, Jerusalén, 1988.

-, "La sociolingüística moderna y el romance temprano", Actes du XVIIIe Congrès International de Linguistique et Philologie Romanes, vol. V, Tübingen, 1988, 11-18. 